\title{
Not Infected but Physically and Mentally Affected: Older Cubans and COVID-19
}

\author{
Jesús E. Menéndez-Jiménez
}

COVID-19 has dominated the conversation this year. Following the first outbreaks in December 2019, it became clear that older adults were predisposed to greater disease severity and death. What occurred in nursing homes across Europe and the Americas was brutal-as much for the older adults themselves as for their families. Many didn't even get to say goodbye.

When the first COVID-19 cases were diagnosed in Cuba in March of this year, I feared for our older adults living in nursing homes. We have 155 nursing homes where 12,368 people live full time, plus 3481 part-time live-ins across the country. Additionally, over 10,000 older adults participate in daily activities at our national network of 295 Senior Centers. $[1,2]$ But by May, there had been just a single outbreak in a nursing home-in Santa Clara city in central Cuba. We got lucky, I thought. After weeks and then months, I realized it wasn't luck, but rather the result of political will, well-designed and implemented protocols and trained health professionals and others dedicated to doing a good job. This was what kept COVID-19 incidence low in our nursing homes.

But COVID-19 isn't just an infectious disease: it impacts people's lives in other ways. In spite of the resilience Cubans have shown in the face of natural disasters and extreme economic circumstances, we are beginning to see the effects-which will continue over timein the population's physical and mental health, especially among the most vulnerable, including older adults.

Prolonged confinement due to lockdown can trigger changes in personal and social relations in a short time, adversely affecting people's mental health. This was less visible at the outset of the pandemic since the priority was saving lives.[3]

Although efforts have been

Prolonged confinement due to lockdown can trigger changes in personal and social relations in a short time, adversely affecting mental health
Moreover, prolonged lack of physical activity can have negative effects that are even harder to overcome later on, such as losing the exercise habit, overweight, pain, falls and fear of falling, among others. Health prevention measures that restrict movement outdoors can also mean that older adults lose autonomy and their social interactions shrink considerably.

According to Dr Francisco Durán, Cuba's National Director of Epidemiology, most deaths between January 1 and April 30, 2020 were due to chronic disease, not COVID-19-38,300 as compared to 64.[7] Cuba has paid close attention to chronic disease as a risk factor for developing severe COVID-19 and prioritized people with cardiovascular or respiratory disease, diabetes, cancer and other chronic conditions. Furthermore, cancer and other chronic disease treatments have been maintained throughout the pandemic.

Less analysis, however, has been conducted around older adults who don't contract COVID-19 and the possible impact of lockdowns on their mental and physical health.

Knowing that overweight, anxiety and low levels of physical activity during lockdown can increase risk for cardiovascular and cerebrovascular disease begs the question: what are we doing about it?

Since April 2020, community-based networks involving public, private and cooperative sector workers have been established to support the most vulnerable, with emphasis on older adults who live alone. Meanwhile, health institutions like Community Mental Health Centers, located in each municipality throughout the country, offer free mental health services. And specialized web pages have been created to provide resources and recommendations to mental health professionals for treating their patients during the pandemic.[8]

Cuban civil society is actively providing support as well. For example, the Cuban Psychological Society launched a unique initiative called 'Psico Grupos' that provides psychological consultations using the WhatsApp platform. The Cuban Geriatrics and Gerontology Society, as part of the PIESPLAZA Project (an initiative co-financed by Cuba and the European Union), provides support to caretakers of older adults in the Plaza de la Revolución municipality of Havana by distributing educational pamphlets detailing how care can be improved for this vulnerable group during the pandemic. These actions make a positive contribution to the mental health of older adults.

In my experience as a geriatrician, I think exercise and physical activity are the best medicine for staving off many physical and psychological health problems-no matter what your age, but especially in older adults. Exercising, even at home, improves mobility, leads to fewer falls and increases 


\section{Viewpoint}

well-being. Given these multiple benefits, I recommend exercise for older adults and counsel families to encourage their older adults to embrace exercise and physical activity during lockdown.

This is also a time to motivate older adults towards self-care to help ameliorate chronic disease complications, promoting steps they can take to assume responsibility for their own well-being. Healthier eating habits, some form of physical activity at home (or in safe places when it's permitted), proper dental hygiene and getting a good night's sleep can all have positive effects.
We need a 'new normal' that incorporates or re-incorporates healthy lifestyles, especially among older adults. Those who attend to the needs of older adults, whether in the health

\section{We need a 'new normal' that incorporates or re- incorporates healthy lifestyles, especially among older adults} sector or the community, have an important role to play in helping them regain their health and positive outlook on life. Even if they never became infected, COVID-19 can have lingering effects-for older adults and in fact, for all of us. - wh

\section{REFERENCES}

1. National Health Statistics and Medical Records Division (CU). Anuario Estadístico de Salud 2019 [Internet]. Havana: Ministry of Public Health (CU); 2020 [cited 2020 Sep 30]. 206 p. Available at: https://files.sld.cu/bvscuba/ files/2020/05/Anuario-Electrónico-Español-2019-ed-2020.pdf. Spanish.

2. Data from Ministry of Public Health (CU). Personal communication. December 2019

3. Ribot Reyes VC, Chang Paredes N, González Castillo AL. Efectos de la COVID-19 en la salud mental de la población. Rev Haban Ciencias Méd [Internet]. 2020 [cited 2020 Aug 31];19(Suppl.):e3307. Available at: http://www.revhaba nera.sld.cu/index.php/rhab/article/view/3307. Spanish.

4. Ayers JW, Leas EC, Johnson DC, PoliakA, Althouse BM, Dredze M, et al. Internet Searches for Acute Anxiety During the Early Stages of the COVID-19 Pandemic. JAMA Intern Med [Internet]. 2020 Aug 24 [cited 2020 Aug 31]. Available at: https://jamanetwork.com/journals/jamainternalmedicine/fullarticle/2769543

5. Encuesta Nacional de Envejecimiento Poblacional 2017 (ENEP 2017) [Internet]. Havana: National Statistics Bureau (CU), Center for Population and Development Studies; 2019 Sep [cited 2020 Sep 18]. 238 p. Available at: http://www .onei.gob.cu/sites/default/files/0.enep-2017_documento_completo.pdf. Spanish.

6. Xue QL. The Fraility Syndrome: Definition and Natural History [Internet]. Clin Geriatr Med. 2011 Feb [cited 2020 Sep 22];27(1):1-15. Available at: https:// www.ncbi.nlm.nih.gov/pmc/articles/PMC3028599/

7. Enfermedades no transmisibles aportan mayor cifra de decesos en Cuba [Internet]. Havana: Prensa Latina; 2020 May 17 [cited 2020 Aug 31]. Available at: https://www.prensa-latina.cu/index.php?o=rn\&id=366727\&SEO=enfermed ades-no-transmisibles-aportan-mayor-cifra-de-decesos-en-cuba. Spanish.

8. INFOMED [Internet]. Havana: Ministry of Public Health (CU); c2020. Especialidades. Psiquiatría. Recomendaciones para los profesionales de la salud mental en el contexto de la COVID-19 en Cuba; [cited 2020 Aug 31]. Available at: https://especialidades.sld.cu/psiquiatria/2020/06/06/recomendaciones-para -los-profesionales-de-la-salud-mental-en-el-contexto-de-la-covid-19-en-cu ba-2/. Spanish.

Submitted: September 8, 2020

Approved for publication: September 26, 2020

Disclosures: None

Correspondence: jmj@infomed.sld.cu 